\title{
A CARTOGRAFIA DE PAISAGENS E A PERSPECTIVA GEOSSISTÊMICA COMO SUBSÍDIOS AO PLANEJAMENTO AMBIENTAL
}

\section{The cartography of landscapes and the geosystemic perspective as subsidies for environmental planning}

\author{
Rafael Cardão Augusto \\ Mestrando do Programa de Pós-Graduação em Geografia da FFP-UERJ \\ rafaelcardao@hotmail.com
}

Artigo recebido em 27/04/2016 e aceito para publicação em 18/06/2016

DOI: $10.12957 /$ tamoios.2016.22644

Resumo A paisagem se constitui num dos principais conceitos balizadores da ciência geográfica, e sua definição passou por diversas reflexões ao longo da história, mantendo-a contextualizada e com relevantes contribuições às teorias e métodos da geografia. $\mathrm{O}$ presente trabalho aborda as repercussões que a perspectiva geossistêmica trouxe ao conceito de paisagem, a partir dos anos 1960. Faz considerações a respeito das tecnologias de Geoprocessamento como ferramentas de análise das paisagens, e por fim trata da Cartografia de Paisagens como um método que integra a proposta multidisciplinar da teoria geossistêmica e as possibilidades multitemáticas das ferramentas de Geoprocessamento, apresentando, desta forma, potencialidades de subsidiar o planejamento ambiental com uma abordagem integradora e analítica para geração de produtos cartográficos. Para o estudo, foram feitos levantamentos bibliográficos de autores que trabalharam com os conceitos e temas propostos.

Palavras-chave: Cartografia de Paisagens; Geossistemas; Geoprocessamento

\begin{abstract}
The landscape is one of the most importants concepts of geographical science, and its definition has undergone several reflections throughout history, keeping it relevant contributions to the theories and methods in geography. This article discusses the impact that the geosystemic perspective brought to the concept of landscape, from the 1960s. And makes considerations about the GIS technologies such as landscapes analysis tools, and finally comes Cartography of Landscapes as a method that integrates multidisciplinary proposal of the geosystemic theory and thematic possibilities of Geoprocessing tools, presenting the potential to subsidize environmental planning with an integrated and analytical approach to the generation of cartographic products. For this study, we conducted a survey of authors who worked with the concepts and topics proposed.
\end{abstract}

Key-words: Cartography of Landscapes; Geosystems;, Geoprocessing 


\section{INTRODUÇÃO}

A paisagem ocupa, cada vez mais, parte importante dos conteúdos de estudos e avaliações de impactos ambientais, planejamento urbano, rural e regional, e iniciativas e propostas de legislação que visam à proteção da natureza. A qualidade das paisagens torna-se avaliação obrigatória em qualquer estudo que traga, no cerne, uma preocupação com a conservação do ambiente (TABACOW \& XAVIER-DA-SILVA, 2010).

Nas perspectivas clássicas de paisagem, os geógrafos a percebiam como a expressão materializada das relações do homem com a natureza, com seus limites atrelando-se à possibilidade visual (SUERTEGARAY, 2001). Ao longo dos anos, distintas correntes de pensamento definiram diferentes perspectivas acerca do conceito de paisagem. Segundo Rodriguez et al (2007), os estudos da paisagem se iniciaram já no século XIX com Humboldt na escola alemã, e Lomonosov e Dokuchaev na escola russo-soviética. Estas escolas definiram a paisagem como um complexo integrado formado por diferentes elementos, e tiveram importantes pensadores como Passarge (1919), Troll (1950), Riábchicov (1976), Sochava (1978), dentre outros.

Pela escola francesa, também no século XIX, La Blache (1921) definia a paisagem como expressão do gênero de vida e cultura. Sua definição em La Blache está bastante presente nas noções de forma e fisionomia, sendo apresentada a partir dos conceitos de gênero de vida, hábito, e adaptação ao meio (NAME, 2010). Posterior à La Blache na escola francesa, Tricart (1950) propôs uma análise da interação ambiental de forma integrada, através da ecodinâmica, relacionada ao conceito de ecossistema, para propor o estudo e análise dos ecótopos. Desta forma, Tricart foi um dos primeiros autores a assinalar uma abordagem sistêmica, ao dar foco à dinâmica e troca de fluxos de matéria e energia.

$\mathrm{Na}$ escola anglo-saxônica, Sauer (1925) analisou a morfologia da paisagem, definindo-a como uma área composta por uma associação distinta de formas, ao mesmo tempo físicas e culturais, adicionando-a ela já um caráter orgânico. Sauer a definia como o objetivo da pesquisa geográfica, com uma identidade formada, antes de mais nada, pela visibilidade da forma, contendo o sítio e a cultura (SAUER, 1925), sendo conceituada apenas como uma representação, definindo assim seu caráter morfológico.

Autores como La Blache e Sauer fundamentaram perspectivas fenomenológicas e dialéticas da paisagem, até as definições de autores contemporâneos como Santos (2008), para quem a paisagem é tudo que a visão alcança, podendo ser concebida como o domínio do visível, formada não apenas por volumes, mas também de cores, movimentos, odores, sons, etc.

Com o tempo, os geógrafos passaram a considerar a paisagem para além da forma. Troll (1950), autor da escola alemã, propôs a criação da Geoecologia da Paisagem, centralizada nos estudos dos aspectos espacial (geográfico) e funcional (ecológico) para o estudo das paisagens (RODRIGUEZ ET AL, 2007, p.20), definindo esta como sendo resultado de um processo de articulação dinâmica entre os elementos constituintes. Posterior a Troll, diversos autores a partir de meados do século XX fazem referência à paisagem como algo além de uma morfologia visível:

A paisagem não é a simples adição de elementos geográficos disparatados. É, em determinada porção do espaço, o resultado da combinação dinâmica, portanto instável, de elementos físicos, biológicos e antrópicos que, reagindo 
dialeticamente uns sobre os outros, fazem da paisagem um conjunto único e indissociável, em perpétua evolução. (BERTRAND, 1971, p.141).

A partir de então a evolução do conceito de paisagem trouxe outras perspectivas, como a de Sochava (1977), que introduziu o conceito de geossistemas nos estudos da paisagem, surgindo assim o aparato teórico robusto da Geoecologia da Paisagem, com enfoque na dinâmica, estrutura e conexões entre os elementos, fundamentando assim as pesquisas de autores mais recentes, como Ross (2006), Rodriguez et al (2007), entre outros. A Geoecologia da Paisagem constitui uma abordagem teórico-metodológica que apresenta um enfoque sistêmico e interdisciplinar, capaz de subsidiar as bases necessárias para o planejamento ambiental (SILVA ET AL, 2010).

Com grande potencial de aplicabilidade na temática ambiental, os produtos obtidos por meio da tecnologia do Sensoriamento Remoto, como imagens de radar e imagens multiespectrais, vêm sendo extensamente utilizados nos últimos anos, tendo apresentado um grande crescimento em razão da expansão dos meios de processamento, dos baixos custos de capital, e pelo fato das imagens possuírem variadas escalas de tempo e de detalhamento espacial.

A interpretação das imagens possibilita a geração de mapas, através de ferramentas computacionais de Geoprocessamento, de onde é possível extrair dados quantitativos que viabilizam uma análise adequada sobre um determinado tema. Um dos enfoques do Geoprocessamento está na Cartografia de Paisagens, que, aproveitando as possibilidades de aplicação do aparato teórico-metodológico da Geoecologia das Paisagens, possui grande potencial de contribuição à temática ambiental.

A presente pesquisa possui um caráter de revisão teórica, que irá perpassar primeiramente por algumas das principais abordagens bibliográficas da paisagem numa perspectiva geossistêmica, seguida de abordagens sobre como o Geoprocessamento se constitui numa importante ferramenta de estudos da paisagem. Por fim, através de uma conceituação do termo Planejamento Ambiental, seguirão propostas teóricas e metodológicas da Cartografia de Paisagens como subsídio ao Planejamento Ambiental, através da abordagem geossistêmica e das ferramentas de Geoprocessamento.

\section{O CONCEITO DE PAISAGEM NUMA PERSPECTIVA GEOSSISTÊMICA}

A preocupação com o ambiente emergiu com intensidade nos anos 1960, sendo estimulada pelas advertências acerca do impacto da atividade humana, e pelos debates a respeito do grau de finitude dos recursos terrestres (GREGORY, 1992, p.188). Diante disso, a partir de meados dos anos 1960, os ramos da Geografia Física passaram a reconhecer a necessidade de estudos dos processos, por causa da maneira pela qual eles estavam aparecendo mais proeminente nas disciplinas correlatas (GREGORY, 1992, p.142), e o estudo destes processos incluía fundamentalmente a integração do homem como um dos principais elementos que atuam no ambiente, somado às forças geológicas, geomorfológicas, pedológicas, hidrológicas, climáticas e biogeográficas como modificadores de processos. Esta visão trouxe contribuições acerca dos estudos integrados e interdisciplinares que se dariam dali para frente. 
Influenciado pela teoria geral dos sistemas de Bertalanffy (1901) e pela Geoecologia das Paisagens de Troll (1950), o geógrafo russo Sochava formulou e propôs o conceito de geossistemas a partir dos anos 1960, assinalando e o incorporando ao estudo das paisagens, visando um entendimento dos processos para além de somente a forma, e fazendo uma crítica à visão puramente morfológica da paisagem:

Em condições normais deve estudar não os componentes da natureza, mas as conexões entre eles: não se deve restringir à morfologia da paisagem e suas subdivisões, mas, de preferência, projetar-se para o estudo da dinâmica, estrutura funcional, conexões, etc. (SOCHAVA, 1977, p.2).

Sochava (1978) define os geossistemas como sistemas dinâmicos, complexos, e hierarquicamente organizados. Deixando clara a consideração da influência antrópica, Sochava (1977, p.7) cita que embora os geossistemas sejam fenômenos naturais, todos os fatores econômicos e sociais, influenciando sua estrutura e peculiaridades espaciais, são tomados em consideração. Rodriguez et al (2007) define geossistema como uma dimensão do espaço terrestre onde os diversos componentes naturais apresentam-se em conexões sistêmicas uns com os outros, possuindo uma integridade definida, interagindo com a esfera cósmica e com a sociedade humana.

A partir das definições de geossistemas, diversos autores começaram a conceituar e analisar a paisagem sob essa perspectiva. A partir de então, as idéias de Sochava fundamentaram a escola siberiana de paisagem, e o seu conceito de geossistema proposto ajudou a consolidar a integração entre as abordagens espacial e funcional da paisagem, dando grande aporte teórico e conceitual à Geoecologia das Paisagens. Apesar de formulada pela escola russa e de fundamentar a escola siberiana, a teoria foi difundida no meio ocidental pela escola francesa, através de Bertrand (1971), com a tradução dos artigos de Sochava, e com seus esquemas taxonômicos propostos.

Sob esta perspectiva, Ross (2006) ressaltou a paisagem como uma unidade homogênea dotada de dinâmica própria, destacando a necessidade de sua análise integrada para auxiliar a aplicação de sua análise a um planejamento ambiental e territorial. Rodriguez et al (2007) dá a noção da integração geoecológica da paisagem, concebendo-a como uma realidade, cujos elementos estão dispostos de maneira tal que subsistem desde o todo, e o todo subsiste desde os elementos, em conexões harmônicas de estrutura e função, deixando explícitas desta forma também as contribuições do paradigma da complexidade de Morin (1982). Esta idéia deixa clara não só a importância da compreensão dos processos num segmento espacial, mas a compreensão do todo, que só pode ser alcançado de maneira interdisciplinar e multiescalar.

A paisagem, segundo Rodriguez et al (2007), possui todas as propriedades e aspectos de um geossistema, como gênese, funcionamento, estrutura, estado, estabilidade, auto-regulação, hierarquia, inputs, outputs, entre outros, considerando sempre o binômio inseparável Sociedade/Natureza. Para este autor, que elabora em sua obra uma rica concepção científica sobre a Geoecologia das Paisagens, incluindo fundamentação teórica, metodológica, epistemologias, taxonomias, e enfoques analítico, estrutural, funcional, evolutivo-dinâmico, histórico, entre outros, a paisagem como um objeto de investigação sob essas premissas dá subsídios ao planejamento ambiental (RODRIGUEZ ET AL, 2007). 


\section{O GEOPROCESSAMENTO COMO FERRAMENTA DE ESTUDOS DA PAISAGEM}

O Geoprocessamento pode ser definido como um conjunto de tecnologias voltadas ao tratamento de informações espaciais para um objetivo específico, fazendo parte deste conjunto, tecnologias como os Sistemas de Informação Geográfica (SIG), o Sensoriamento Remoto, entre outros. Segundo Florenzano (2011), o SIG é um sistema computacional que permite armazenar, em forma de banco de dados, processar, integrar, analisar, calcular áreas, visualizar e representar, em forma de mapas, informações georreferenciadas, que possuem uma localização geográfica definida por um sistema de coordenadas. Pode-se dizer, portanto, que o SIG é o tipo de sistema que melhor viabiliza o Geoprocessamento.

Sobre o Sensoriamento Remoto, pode-se entender, segundo Florenzano (2011), como uma tecnologia que permite obter imagens - e outros tipos de dados - da superfície terrestre, por meio da captação e do registro da energia refletida ou emitida pela superfície, por meio dos sensores de satélites localizados em volta da Terra. É capaz de fazer, portanto, um processo de aquisição de informação sem que seja necessário o contato direto entre o sensor e o alvo na superfície terrestre. Estas imagens são destinadas, entre outras funções, à utilização nas ferramentas de SIG, que fazem o processamento dos dados georreferenciados, desde a sua coleta até a geração de saídas na forma de mapas convencionais, relatórios e arquivos digitais, devendo prever recursos para estocagem, gerenciamento, manipulação e análise desses dados (CÂMARA, 2001).

As imagens de Sensoriamento Remoto, como fonte de dados da superfície terrestre, são cada vez mais utilizadas para a elaboração de diferentes tipos de mapas, com facilidade de acesso e a um custo relativamente baixo, e com uma sistemática bastante satisfatória para estudos de diversas naturezas que pode apresentar grande importância. Buscando uma relação entre os estudos geoecológicos e as novas geotecnologias, Bertrand (1971) já apontava que as imagens aéreas constituíam um apoio precioso por fornecer uma visão sintética e instantânea das paisagens.

As imagens obtidas através do Sensoriamento Remoto proporcionam uma visão de conjunto multitemporal e multiescalar de extensas áreas da superfície terrestre. Esta visão sinóptica da paisagem possibilita seu monitoramento, e desenvolve estudos regionais e integrados, envolvendo vários campos do conhecimento (FLORENZANO, 2005). A fotografia aérea é freqüentemente utilizada para retratar os ecossistemas que compõem a paisagem, bem como sua fronteira (CASIMIRO, 2000). A retratação dos diferentes ecossistemas e das fronteiras proporciona uma capacidade de quantificar a estrutura da paisagem, que é um pré-requisito para o estudo de sua função e mudança.

Sendo assim, além das possibilidades de análise da estrutura e funcionamento da paisagem, o Geoprocessamento adere também o viés ambiental devido a sua capacidade de monitoramento multitemporal, caracterização multiescalar, e abordagem interdisciplinar, permitindo uma análise integrada através da criação e manuseio de camadas espaciais multitemáticas, como mapas de geologia, geomorfologia, uso e cobertura da terra, vegetação, hidrologia, climatologia, entre outras.

O uso das imagens de satélite em conjunto com os SIG tem o potencial de mostrar os ambientes e a sua transformação, destacam os impactos causados por fenômenos naturais como as inundações e a erosão do solo, freqüentemente agravados 
pela intervenção do homem, e antrópicos, como os desmatamentos, as queimadas, a expansão urbana, ou outras alterações do uso e da ocupação da terra (FLORENZANO, 2002). Desta forma destaca-se como o avanço das ferramentas de SIG e de Sensoriamento Remoto vêm contribuindo efetivamente para a integração e análises mais complexas, se apresentando como importantes subsídios para a tomada de decisões quanto às questões ambientais.

\section{A CARTOGRAFIA DE PAISAGENS COMO SUBSÍdIO AO PLANEJAMENTO AMBIENTAL}

Diversos autores conceituam planejamento ambiental, termo que ainda não possui uma definição precisa, porém que sempre denota algo envolvendo a administração pública e a aplicação de políticas que consideram questões sociais, físicas e bióticas no espaço. Segundo Santos (2004, p.28), o planejamento ambiental consiste em buscar o desenvolvimento harmônico de uma região, aliado à manutenção da qualidade do ambiente físico, biológico e social, prevendo e indicando mudanças no uso da terra, contemplando medidas de proteção aos ecossistemas com pouca interferência humana, definindo e espacializando ocupações, ações e atividades, de acordo com as características locais.

Para Lanna (1995, apud TEIXEIRA, 1998, p.42), o planejamento ambiental é um processo organizado de obtenção de informações, reflexão sobre os problemas e potencialidades de uma região, definição de metas e objetivos, definição de estratégias de ação, definição de projetos, atividades e ações, bem como definição do sistema de monitoramento e avaliação que irá retroalimentar o processo, visando organizar a atividade sócio-econômica no espaço, respeitando suas funções ecológicas.

Diante disso, o planejamento ambiental envolve a organização e aplicação de políticas que consideram a relativa manutenção do equilíbrio sistêmico de uma determinada porção do espaço, levando em consideração o todo, em harmonia com os interesses econômicos que se deseja aplicar. Desta forma, há grande apelo interdisciplinar e multiescalar para que um planejamento ambiental seja organizado de forma adequada, com a Geoecologia das Paisagens oferecendo potencial aporte teórico e metodológico voltado para este sentido.

Cavalcanti (2014) ressalta que em geral os estudos ambientais carecem de fundamentação cartográfica, sobretudo com vistas ao suporte de atividades de planejamento e gestão do ambiente (p.5). Com intuito de propiciar as bases para o planejamento ambiental, um dos objetivos da Geoecologia das Paisagens é desenvolver uma cartografia das unidades de paisagem do território. A Cartografia de Paisagens, área que compreende a Cartografia Ambiental (CAVALCANTI, 2014, p.6), pressupõe compreender uma visão integrada dos elementos e processos do ambiente, sob a perspectiva geossistêmica da paisagem.

A Cartografia de Paisagens, denominada também Mapeamento de Geossistemas, ou Cartografia Geoambiental, é uma atividade de caráter físico-geográfico, e está preocupada com a representação de complexos naturais, também chamados de geossistemas, que compreendem áreas naturais resultantes da interação entre os componentes da natureza, influenciados em maior ou menor grau pela sociedade (CAVALCANTI, 2014, p.5). 
Desde o início do estudo de geossistemas, autores se preocuparam em definir taxonomias e categorias analíticas da paisagem, baseadas na escala e na homogeneidade de elementos, formas e padrões funcionais, passíveis de delimitação cartográfica. Bertrand (1971) definiu um sistema taxonômico com unidades superiores - zonas, domínios, regiões naturais - e unidades inferiores - geossistemas, geofácies, geótopo onde o termo geossistema aparece como uma categoria, e onde ambas categorias são propostas em função da escala temporo-espacial. Sochava $(1977,1978)$ definiu os critérios para classificação de geossistemas, seus níveis de organização, e sua divisão taxonômica, de acordo com diferentes categorias de geossistemas, definindo as unidades por ordem de grandeza espacial. Os estudos de Monteiro (1982, 1995, 2000), demonstram também as possibilidades em se fazer a representação dos geossistemas, realizada, por exemplo, por organogramas representativos de geômeros (RODRIGUES, 2001).

Desde então, alguns autores se preocuparam em desenvolver princípios técnicos e metodológicos de classificação e representação de paisagens, voltados para a geração de mapas que contribuam para uma visão integrada do ambiente. Na obra Geoecologia das Paisagens, Rodriguez et al (2007) propõe as unidades geoecológicas da paisagem, em duas etapas: a regionalização geoecológica da paisagem, e as unidades locais de paisagem. Na primeira etapa, o autor define como níveis espaciais da superfície geográfica o global, o regional e o local, com dois procedimentos científicos a serem tomados: a regionalização das paisagens, que consiste em criar um sistema de divisão de unidades de paisagem, e a tipologia de paisagens, que consiste em dividir os objetos semelhantes ou análogos, de acordo com traços comuns.

Estes procedimentos subsidiam as tipologias de paisagem - classes, tipos, grupos e espécies - determinadas por diferentes níveis estruturais e funcionais. Quanto menor o nível tipológico, menor a escala geográfica, e mais detalhados os índices diagnósticos, que correspondem às sobreposições de diversos elementos interdisciplinares, envolvendo fatores e variáveis climáticas, geológicas, geomorfológicas, pedológicas, hídricas, bióticas e antrópicas (RODRIGUEZ ET AL, 2007, p.80), tornando mais específicos, peculiares e homogêneos os elementos e processos contidos em cada menor unidade de paisagem, contribuindo assim para sua melhor compreensão. É através da referida distinção e classificação das paisagens, que Rodriguez (2007, p.89) cita a cartografia das paisagens como o objeto final, consistindo na aplicação dos métodos de distinção e elaboração dos diferentes tipos de mapas de paisagem, através de diversas etapas, desde os trabalhos de campo até a confecção do produto final (RODRIGUEZ ET AL, 2007, pp.89-107).

Com semelhante esforço, Cavalcanti (2014) propôs em sua obra, Cartografia de Paisagens, alguns princípios metodológicos, técnicas de representação, e critérios para a observação da paisagem. Em seu sistema de unidades taxonômicas, Cavalcanti (2014, p. 33) define quatro táxons - zonas; domínios de natureza; famílias de ecossistemas; minibiomas - adaptados de Ab'Saber (2006), com dimensões e condicionantes que vão de uma escala geográfica maior no primeiro táxon, até uma escala menor no táxon minibioma, sendo este proposto por ele como a menor unidade de paisagem. É no minibioma onde mais condicionantes se sobrepõe, envolvendo diferentes elementos componentes, que devem ser avaliados conjuntamente através de um raciocínio sintético: clima, formas de relevo, litotipo, drenagem, vegetação, solos e uso da terra.

Segundo Cavalcanti (2014, p.34), é este raciocínio que pressupõe a identificação de paisagens, envolvendo três principais procedimentos: a delimitação da área de estudo, a avaliação do contexto, e a identificação dos principais contrastes paisagísticos 
observáveis. As técnicas para representação destas paisagens envolvem desde trabalhos de campo, até interpretação de dados temáticos, imagens, e o método mais completo por ele abordado: a modelagem cartográfica, baseada na utilização de sensoriamento remoto e geoprocessamento, que pode contemplar também todas as etapas anteriores (CAVALCANTI, 2014, p.49).

Bem específico a respeito da temática de geoprocessamento, Lang \& Blaschke (2009), em sua obra Análise da Paisagem com SIG, demonstra as contribuições do sensoriamento remoto e do geoprocessamento na observação, processamento, integração, análise e representação de paisagens, através da manipulação de diferentes dados temáticos georreferenciados em ferramentas de Sistemas de Informação Geográfica (SIG). Além dos autores citados, outros nomes desenvolveram métodos de classificação de paisagens, como Ab'Saber (2003), ao criar um sistema de classificação dos domínios de paisagem no Brasil.

Como exemplo de aplicação dos métodos anteriormente propostos, alguns autores no meio acadêmico vêm dispostos a contribuir com a temática da paisagem, através da geração de produtos cartográficos voltados para subsidiar tomadas de decisão a respeito de questões ambientais, como Seabra (2012), que propôs uma análise da paisagem em apoio aos estudos de favorabilidade à recuperação florestal na bacia hidrográfica do rio São João, no estado do Rio de Janeiro.

Para além do Brasil, Carrão et al (2001) propôs o cálculo de indicadores de paisagem em ambiente SIG, destacando a importância destes indicadores para o planejamento ambiental, uma vez que a avaliação das conseqüências das atividades humanas no ambiente pode ser expressa em termos de uso do solo e de variações na estrutura de paisagem, que podem ser quantificadas através de tais indicadores.

Tais exemplos demonstram o nível de aplicabilidade e de contribuição que a Cartografia de Paisagens, e a geração de mapas temáticos, possuem para uma compreensão integrada e interdisciplinar do ambiente, com o objetivo de fundamentar e apoiar decisões voltadas à recuperação ou preservação ambiental.

\section{CONCLUSÕES}

A evolução do conceito de paisagem para além de somente a forma visual, a incorporação da abordagem geossistêmica, e a fundamentação da Geoecologia das Paisagens foram determinantes para uma melhor compreensão do ambiente, através de tal ótica, com a Cartografia de Paisagens como instrumento que dá subsídios a um planejamento ambiental de qualidade.

As propostas elaboradas pelos diferentes autores contribuíram como legados teóricos ou aplicações metodológicas da Cartografia de Paisagens, que, ao aliar a perspectiva multidisciplinar da teoria geossistêmica e a perspectiva multitemática das ferramentas de Geoprocessamento, possui um caráter ambiental. Classificar e representar uma paisagem pressupõe a análise vertical de todas as forças elementares que atuam e interagem dentro de um determinado recorte espacial, através da sobreposição de temas multidisciplinares que irão refletir a homogeneidade, complexidade e particularidade dos processos presentes em cada unidade de paisagem.

É com o embasamento teórico destes conceitos, dos métodos e das técnicas de análise e representação das paisagens, e com o aproveitamento das ferramentas que 
viabilizam esses procedimentos, que se pode, com um objetivo definido de contribuição à sociedade e ao ambiente, gerar produtos que subsidiem iniciativas de planejamento ambiental, com o intuito de compreender, respeitar e preservar o equilíbrio dos sistemas naturais.

\section{REFERÊNCIAS BIBLIOGRÁFICAS}

AB'SABER, A.N. Os domínios de natureza no Brasil: Potencialidades paisagísticas. São Paulo: Ateliê Editorial. 2003. 159p.

AB’SABER, A.N. Ecossistemas do Brasil. São Paulo: Metalivros. 2006. 300p.

BERTALANFFY, L.V. Teoria Geral dos Sistemas. Rio de Janeiro: Vozes, [2008 (1901)]

BERTRAND, G. Paisagem e Geografia Física Global: esboço metodológico. São Paulo: Revista IG-USP. Caderno de Ciências da Terra. n.13. 1971.

CÂMARA, G.; MONTEIRO, A.M.V.; MEDEIROS, J.S. de. Fundamentos epistemológicos da ciência da Geoinformação. In: CÂMARA, Gilberto; DAVIS, Clodoveu; MONTEIRO, Antônio Miguel Vieira (Ed.). Introdução à ciência da Geoinformação. São José dos Campos: INPE, 2001. p. 16. Publicado como: INPE8565-PRE/4309. Disponível na biblioteca digital URLib: http://mtc12.sid.inpe.br/rep/sid.inpe.br/sergio/2004/04.19.14.42. Acesso em: 24 nov. 2015.

CARRÃO, H.; CAETANO, M.; NEVES, N. LANDIC: Cálculo de indicadores de paisagem em ambiente SIG. In: Encontro de Utilizadores de Informação Geográfica ESIG 2001, 6., Oeiras, Portugal, 28-30 nov., 2001. Anais. Lisboa: Associação dos Utilizadores de Sistemas de Informação Geográfica - USIG, 2001. Acessível em http://esig2001.tripod.com. Consultado em 2/10/2015.

CASIMIRO, P.J.C.C. Uso do Solo - Ecologia da Paisagem: Perspectivas de uma abordagem do estudo da paisagem em Geografia. In: Revista DGPR, Número 2. Lisboa: FCSH-UNL. 2000. pp.45-66.

CAVALCANTI, L.C.S. Cartografia de Paisagens: Fundamentos. São Paulo: Oficina de Textos, 2014.

FLORENZANO, T.G. Imagens de satélite para estudos ambientais. São Paulo: Oficina de Textos, 2002.

FLORENZANO, T.G. Geotecnologias na Geografia aplicada: difusão e acesso. In: Revista do Departamento de Geografia. n.17. 2005. pp.24-29.

FLORENZANO, T.G. Iniciação em Sensoriamento Remoto. $3^{a}$ Edição. São Paulo: Oficina de Textos, 2011. 128p.

GREGORY, K.J. A Natureza da Geografia Física. Rio de Janeiro: Bertrand Brasil, 1992. 367p.

LA BLACHE, P.V. Princípios de geografia humana. Lisboa: Edições Cosmos. 1921. $328 \mathrm{p}$.

LANG, S.; BLASCHKE, T. Análise da paisagem com SIG. São Paulo: Oficina de Textos. 2009. 424p. 
LANNA, A.E.L. Gerenciamento de bacia hidrográfica: aspectos conceituais e metodológicos. Brasília: IBAMA, 1995. 171p.

MORIN, E. Introdução ao pensamento complexo. In: Ciência com Consciência. Rio de Janeiro: Bertrand Brasil, [2003 (1982)].

NAME, L. O conceito de paisagem na geografia e sua relação com o conceito de cultura. Salvador: Geotextos. V.6. 2010. p 163-186.

RIÁBCHICOV, A.M. Estructura y Dinámica de La Esfera Geográfica: Su desarollo natural y transformación por el hombre. Traducido del Ruso para Español por Isabel Alvarez Moran. Editorial MIR. Moscou. 1976.

RODRIGUES, C. A teoria geossistêmica e sua contribuição aos estudos geográficos e ambientais. Revista do Departamento de Geografia, n. 14, São Paulo. 2001.

RODRIGUEZ, J.M.M.; SILVA, E.V. e CAVALCANTI, A.P.B. Geoecologia das paisagens: uma visão geossistêmica da análise ambiental. 2 ed. Fortaleza. Edições UFC. 2007. 222p.

ROSS, J. L. S. Ecogeografia do Brasil: subsídios para planejamento ambiental. São Paulo: Oficina de textos. 2006. 208p.

SANTOS, R.F. Planejamento Ambiental: teoria e prática. São Paulo: Oficina de Textos. 2004. 184p.

SAUER, C.O. Morfologia da Paisagem. Rio de Janeiro: EDUERJ. [1998 (1925)].

SEABRA, V.S. Análise da Paisagem em apoio aos estudos de favorabilidade à recuperação florestal na Bacia Hidrográfica do Rio São João. Tese (Doutorado em Geografia). Rio de Janeiro: Universidade Federal do Rio de Janeiro, 2012.

SILVA, E.V.; GORAYEB,A.; RODRIGUEZ, J.M.M. Geoecologia das Paisagens, Cartografia Temática e Gestão Participativa: estratégias de elaboração de planos diretores municipais. II Seminário Ibero Americano de Geografia Física. Coimbra: 2010

SOCHAVA, V.B. O estudo de geossistemas. In: Métodos em questão. São Paulo, 1977.

SOCHAVA, V.B. Por uma teoria de classificação de geossistemas da vida terrestre. São Paulo: Instituto de Geografia USP, 1978.

SUERTEGARAY, D.M.A. Espaço geográfico uno e múltiplo. Barcelona: Revista Geografia y Ciências Sociales. n.93. 2001.

TABACOW J.W.; XAVIER-DA-SILVA, J. Geoprocessamento aplicado à análise da fragmentação da paisagem na Ilha de Santa Catarina. In: XAVIER-DA-SILVA, J.; ZAIDAN, R.T. (Orgs.). Geoprocesssamento e Meio Ambiente. Rio de Janeiro: Bertrand Brasil, 2010. pp.35-70.

TEIXEIRA, M.B. Planejamento Ambiental: Referencial básico e roteiro para formulação do plano ambiental municipal. Dissertação de Mestrado. Porto Alegre: UFRGS. 1998.

TRICART, J. Ecodinâmica. Rio de Janeiro: IBGE/SUPREN, 1977.

TROLL, C. A paisagem geográfica e sua investigação. In: Espaço e cultura. Rio de Janeiro: UERJ, NEPEC, n.2. jun. [1997 (1950)] 